\title{
MUTATIONS IN THREE SPECIES OF DROSOPHILA
}

\author{
CHARLES W. METZ \\ Station for Experimental Evolution, Cold Spring Harbor, New York
}

[Received August 19, 1916]

TABLE OF CONTENTS

PAGE

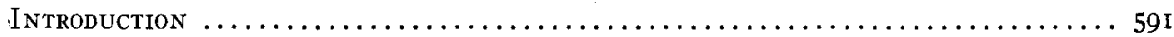

Mutants in Drosophila virilis Sturtevant MSS.................... 592

Description of mutant characters..................... 593

Origin and genetic behavior of mutants.................. 593

Linkage $\ldots \ldots \ldots \ldots \ldots \ldots \ldots \ldots \ldots \ldots \ldots \ldots \ldots \ldots \ldots \ldots \ldots \ldots \ldots \ldots$

Comparison between mutants in $D$. virilis and $D$. ampelophila.......602

Mutants in Drosophila obscura Fall. ............................6 604

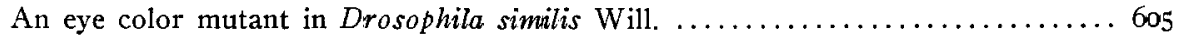

Mutability in different species of Drosophila....................6606

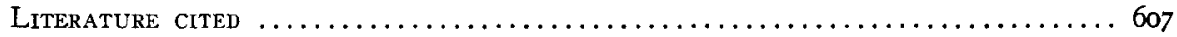

\section{INTRODUCTION}

In a preliminary paper (METZ and METZ I915), two mutations were recorded in Drosophila tripunctata Loew., and an undescribed species called "species B." Since that paper was written D. tripunctata has been discarded because of its poor breeding qualities, and has been replaced by another species, Drosophila obscura Fall., which, together with "species B," has been bred in large numbers during the last eighteen months. In both of these species mutations have occurred within this time. D. obscura has given rise to at least three, and "species B" to at least twelve. In addition, an eye color mutant has been found in a third species that was collected for cytological purposes and not bred extensively. Considering all four species together, nineteen mutants have appeared in our cultures.

The most interesting of the mutants, at the present time, are the twelve in "species B,"-or, as I may now call it, Drosophila virilis Sturtevant MSS. ${ }^{1}$ - because in this species at least three groups of linked factors have already been obtained and it seems probable that more will be evident when all of the twelve factors are tested out. Thus far only

1 This species is soon to be described by Dr. ISturtevant, to whom I am indebted for permission to use his manuscript name. 
six have been fully tested. Three of these are sex-linked, two others are non-sex-linked and linked together, and the sixth is neither sexlinked nor linked to either of the others. In a subsequent paper I hope to report more fully upon the linkage phenomena when additional factors are studied, and shall here confine myself mainly to a description of the various mutant characters and a brief account of their inheritance. ${ }^{2}$

MUTANTS IN DROSOPHILA VIRILIS STURTEVANT MSS.

Normal specimens of this species are dull brown in color with dark red eyes and slightly shaded wings. The males have no sex combs and neither sex has any color pattern on the body save four faint, dark stripes running longitudinally on the dorsal part of the thorax. The mutants, in the order of their appearance, are as follows:
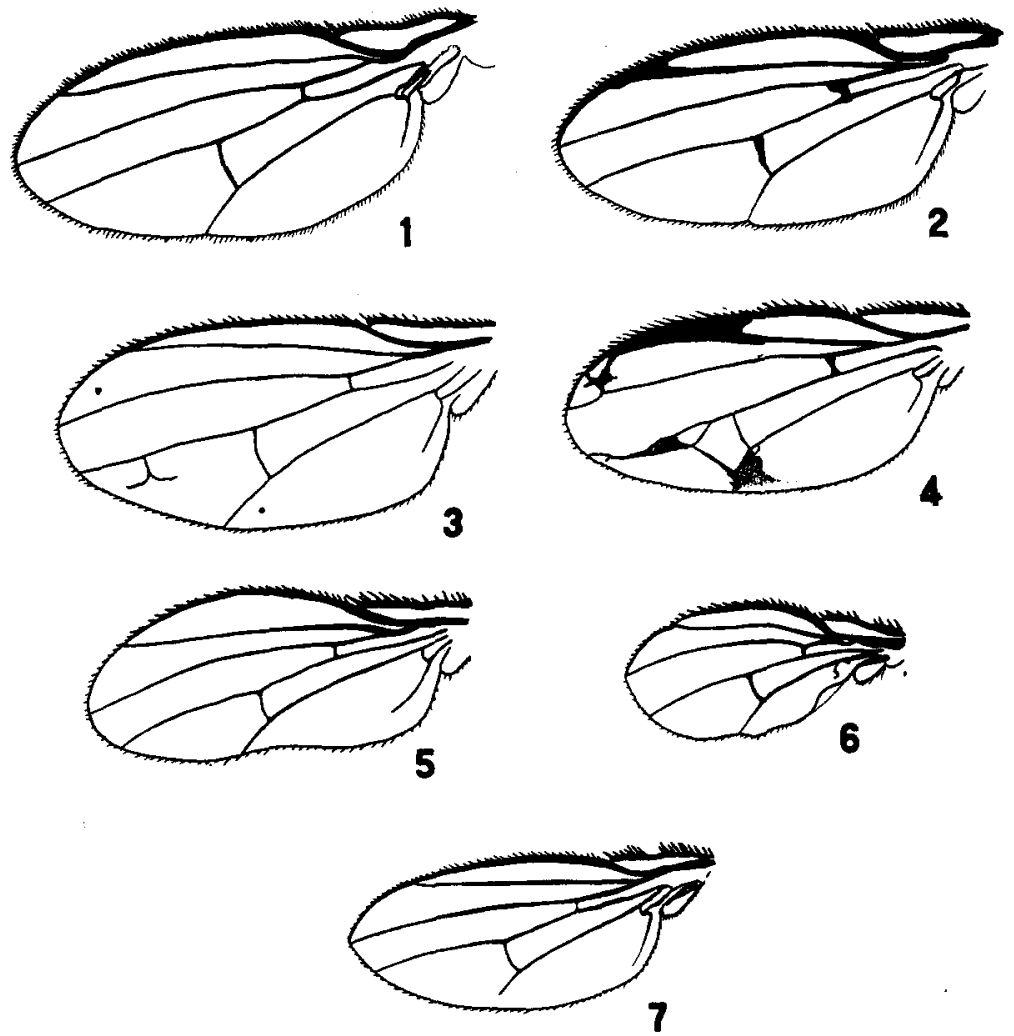

Figure I. Normal wing of Drosophila virilis Sturtevant MSS. Figure 2. Confluent wing. Figure 3. Axillary wing. Figure 4. Confluent axillary wing. Figures 5 and 6. Two types of concave wing. Figure 7 . Acute wing.

2 I am indebted to my wife for making the accompanying drawings, and for other assistance during the course of the work. Acknowledgment is also due to Mr. Joseph KRAFKA for aid in the breeding work. 
Confluent (figure 2). Non-sex-linked, dominant; wing veins modified. This was described in a previous paper (Metz and Metz 1915). Axillary (figure 3). Non-sex-linked. Wing veins modified by accessory veins or branches, mostly in the apical half or near the inner margin of the wing; a variable character.

Concave (figures 5 and 6). Non-sex-linked recessive. Wing shape and size modified; one or both wings concave instead of convex on the inner margin, or else reduced in size; hairs on arista curled instead of straight.

Morula. Non-sex-linked recessive. Ommatidia of the eye irregularly crowded together instead of symmetrically arranged in rows.

$Y$ ellow. Sex-linked recessive. Entire fly yellow instead of dark brown.

Acute (figure 7). Non-sex-linked recessive. Wing shape and size modified; wings much shorter and narrower than normal, and pointed instead of rounded at the apex; the fifth vein frequently not reaching the margin; anterior pair of orbital bristles often absent.

Steel. Non-sex-linked recessive. An iridescent, metallic, steel-colored spot in the center of the eye.

Bald. Non-sex-linked dominant. Bristles around the ocelli, and frequently the ocelli also, reduced or absent.

Black. Non-sex-linked recessive. Body, legs and wings black instead of dark brown; especially noticeable in the wings.

Glazed. Sex-linked recessive. Eyes with a varnished appearance as if freshly coated with shellac, and with the ommatidia greatly disarranged.

Magenta. Sex-linked recessive. Eye color dark purplish red or magenta, instead of the normal red.

Forked. Sex-linked recessive. Bristles of the head and thorax aborted, twisted and forked, giving a singed appearance.

\section{ORIGIN AND GENETIC BEHAVIOR OF MUTANTS}

The first mutant to appear in my cultures of virilis was confluent, which arose in July or August, I9I4. Its origin and behavior have been described in a previous paper (METz and Metz 1915), and it is only necessary here to add some further data in support of the conclusion previously expressed, that confluent when present in duplex ("double dose") has a lethal effect. This conclusion was based upon the fact that no homozygous confluent flies could be obtained, and that heterozygous flies when inbred give a ratio of two confluents to one normal, instead of 
the expected $3: \mathrm{I}$. Subsequent experiments have borne out this conclusion in every way. Not a single homozygous fly has been found

TABLE I a

Confuent by normal.

\begin{tabular}{c|r|r}
\hline $\begin{array}{c}\text { Culture } \\
\text { number }\end{array}$ & Normal & Confluent \\
\hline 2033 & 132 & I10 \\
2122 & 13 & 10 \\
2127 & 10 & 9 \\
2138 & 43 & 36 \\
2148 & 10 & 15 \\
2150 & 45 & 37 \\
2151 & 61 & 42 \\
2156 & 39 & 14 \\
2159 & 50 & 77 \\
2160 & 32 & 26 \\
2170 & 26 & 38 \\
2171 & 19 & 10 \\
2176 & 34 & 30 \\
2178 & 14 & 12 \\
2183 & 29 & 26 \\
2184 & 27 & 12 \\
2185 & 12 & 23 \\
2186 & 14 & 16 \\
2187 & 73 & 47 \\
2201 & 22 & 12 \\
2203 & 28 & 27 \\
2217 & 62 & 47 \\
\hline Total & 795 & 676 \\
\hline & &
\end{tabular}

TABLE I b

Confuent by confluent, from confluent by confuent.

\begin{tabular}{c|c|c}
\hline $\begin{array}{c}\text { Culture } \\
\text { number }\end{array}$ & Normal & Confluent \\
\cline { 1 - 3 } I327 & $2 \mathrm{I}$ & 36 \\
2025 & 29 & 50 \\
2024 & 73 & 98 \\
2026 & 43 & 58 \\
2027 & 19 & 23 \\
2028 & $3 \mathrm{I}$ & 90 \\
2030 & 44 & 73 \\
2032 & 14 & 36 \\
2048 & 58 & 99 \\
2050 & 33 & 40 \\
2061 & 45 & $6 \mathrm{I}$ \\
2105 & 13 & 20 \\
2106 & 8 & 13 \\
2107 & 3 & 7 \\
2108 & 17 & 36 \\
2109 & 32 & 46 \\
2110 & 23 & 63 \\
$211 \mathrm{I}$ & 24 & $4 \mathrm{I}$ \\
2112 & 20 & $5 \mathrm{I}$ \\
2158 & 19 & 47 \\
\hline Total & 569 & 988 \\
\hline
\end{tabular}

Table i c

Confluent by confuent from confluent by normal.

\begin{tabular}{c|c:c}
\hline $\begin{array}{c}\text { Culture } \\
\text { number }\end{array}$ & Normal & Confluent \\
\cline { 1 - 2 } I34I & $5 \mathrm{I}$ & 74 \\
2072 & II & 17 \\
2168 & 20 & 30 \\
2169 & 20 & 26 \\
2174 & 6 & 19 \\
V269 & 52 & 88 \\
V272 & 17 & 23 \\
V277 & 23 & 55 \\
V278 & I6 & 20 \\
V286 & 45 & 76 \\
\hline Total & 261 & 428 \\
\hline
\end{tabular}


among the hundreds I have tested during the two years (over thirty generations) since this mutant appeared. And the ratios have consistently been such as to indicate the absence of the homozygous class in matings of confluent by confluent. Some of these results taken at random from my records are shown in table I. Three types of matings are given here for comparison: (a) confluent by normal, (b) confluent by confluent, in which the parents are derived from confluent by confluent matings, and (c) confluent by confluent, in which the parents are derived from confluent by normal. According to expectation some of the matings in (a) and (b) should give only confluent offspring while in (c) they should all give three confluents to one normal. In reality no pair has given a purely confluent family; and the ratios in (c) are approximately $2: \mathrm{I}$ instead of $3: \mathrm{I}$. Furthermore the ratios in (b) are just like those in (c), indicating that the parents are alike (heterozygous) in both cases, and that no homozygous flies have appeared. Only one alternative to this explanation occurs to me,--namely, that homozygous flies are produced, but are sterile. This however is made very improbable by the fact that practically all of the confluent flies breed readily and may be tested by mating in pairs.

The second mutant character, axillary, appeared in a normal mass culture during September, I9I5. It presents many irregularities both in its manifestations and in its genetic behavior. In pure stock it may vary from a condition in which several extra veins and branches are present in each wing, to one in which only the slightest trace of a branch or extra vein may be seen; or it may be entirely lacking in a portion of the flies. In behavior axillary is usually an irregular recessive, but frequently it shows itself to a slight extent in a few heterozygous individuals. These features are brought out by the data in table 2 . It is

TABLE 2 a

Axillary by normal.

\begin{tabular}{c|c|c}
\hline $\begin{array}{c}\text { Culture } \\
\text { number }\end{array}$ & Axillary & Normal \\
\cline { 1 - 1 } $\begin{array}{c}\text { I378 } \\
2173\end{array}$ & 26 & 77 \\
2200 & 19 & 60 \\
Total & 10 & 66 \\
\hline
\end{tabular}

TABLE $2 \mathrm{~b}$ Axillary by axillary.

\begin{tabular}{c|c|c}
\hline $\begin{array}{c}\text { Culture } \\
\text { number }\end{array}$ & Axillary & Normal \\
\hline 2075 & IO & 6 \\
$2 \mathrm{I} 95$ & $3 \mathrm{I}$ & 29 \\
$22 \mathrm{I} 2$ & 16 & 0 \\
\hline Total & 57 & 44 \\
\hline
\end{tabular}

not improbable that axillary depends upon, or is decidedly influenced by, several factors, most of which I have not yet located. Certainly it is greatly affected by at least one factor other than the axillary factor 
itself. This factor is confluent. When in the presence of confluent, axillary, instead of behaving as a recessive, becomes an almost complete dominant. This is shown in table 3. When axillary flies are mated to

TABLE 3 a

Confuent by axillary.

\begin{tabular}{c|c|c|c|c}
$\begin{array}{c}\text { Culture } \\
\text { number }\end{array}$ & $\begin{array}{c}\text { Confluent } \\
\text { axillary }\end{array}$ & Normal & Confluent & Axillary \\
\hline $2 \mathrm{I} 27$ & 6 & 9 & 3 & $\mathrm{I}$ \\
$2 \mathrm{I} 70$ & 28 & $\mathrm{I} 8$ & 10 & 8 \\
\hline Total & 34 & 27 & $\mathrm{I}$ & $\frac{9}{2}$ \\
\hline
\end{tabular}

TABLE $3 \mathrm{~b}$

Confiuent axillary (heterozygous) by normal.

\begin{tabular}{|c|c|c|c|c|}
\hline $\begin{array}{l}\text { Culture } \\
\text { number }\end{array}$ & $\begin{array}{l}\text { Confluent } \\
\text { axillary }\end{array}$ & Normal & Confluent & Axillary \\
\hline 2148 & 8 & ro & 7 & 0 \\
\hline 2150 & 22 & 45 & I5 & 0 \\
\hline $215 \mathrm{I}$ & 30 & 60 & 12 & I \\
\hline 2159 & 34 & 77 & 16 & o \\
\hline $217 I$ & 4 & 19 & 6 & 0 \\
\hline 2176 & 23 & 27 & 7 & 7 \\
\hline 2178 & 5 & 12 & 7 & 2 \\
\hline 2185 & I3 & $\mathrm{I} 2$ & 10 & o \\
\hline 2186 & I2 & I4 & 4 & 0 \\
\hline $220 \mathrm{I}$ & 5 & 22 & 7 & 0 \\
\hline 2202 & 2 & I 8 & 3 & 0 \\
\hline 2203 & It & 28 & 10 & 0 \\
\hline 2217 & $3 \mathrm{I}$ & 60 & 3 & I \\
\hline 2206 & 18 & 35 & 8 & I \\
\hline Total & 224 & 459 & 115 & I2 \\
\hline
\end{tabular}

normals they give from five to twenty-five percent of axillary in $F_{1}$, and when axillary flies are inbred (pure stock) they give about fifty or sixty percent axillary; but when axillary flies are mated to confluent, or confluent axillary (heterozygous) to normal (it makes no difference which way the cross is made) the percentage of axillary is greatly increased and nearly all of the axillary flies are in the confluent class. Furthermore nearly all of these confluent axillary flies show a greatly exaggerated effect of both confluent and axillary, (compare figures 2 and 3 with figure 4). This peculiar interaction of factors is similar in a general way to many found in Drosophila ampelophila and other organisms, except that in the latter, so far as I know, dominance and 
recessiveness are not affected (see Morgan, Sturtevant, Muller and BRIDGES I9I 5 , p. 45).

Among the other six non-sex-linked characters five (concave, morula, acute, steel and black) are simple recessives and were each observed in several individuals at their initial appearance. Concave arose in a normal stock culture during September 1915. One concave female from this culture, when mated to normal brothers, gave 64 normal and 17 concave offspring, from which the present stock is descended. Until very recently concave has been looked upon as a variable character, easily affected by the environment, because the characteristic (wing shape) used to distinguish it, was not at all regular in appearance (figures 5 and 6). But I have just discovered that the curled hairs on the arista provide a constant and easily recognizable diagnostic character that will make future experiments relatively simple.

The history of morula is much like the early history of concave. Five morula flies of both sexes appeared in a mass culture and gave rise to the strain now in use. Like axillary, morula sometimes fails to exhibit itself even in homozygous flies, and the ratios are correspondingly distorted (table 4 ).

TABLE 4

Morula by morula, pure stock.

\begin{tabular}{c|c|c}
$\begin{array}{c}\text { Culture } \\
\text { number }\end{array}$ & Morula & Normal \\
\cline { 1 - 2 } I352 & $\mathbf{5 2}$ & 7 \\
I355 & I3 & 0 \\
I356 & $4 \mathrm{I}$ & 46 \\
I37I & I30 & 0 \\
2040 & I02 & 25 \\
2044 & 38 & 3 \\
2047 & 14 & 34 \\
2054 & 31 & 1 \\
VII & III & 0 \\
VI9 & 6 & 0 \\
V6I & 29 & 5 \\
V69 & I06 & 0 \\
V83 & 48 & 2.5 \\
\hline Total & 711 & 146 \\
\hline
\end{tabular}

The character acute appeared in concave stock some time in the early spring of 1916 , and was at first thought to be a modification of concave; but when the constancy of this particular type was noticed it was sep- 
arated from concave and has subsequently bred true. ${ }^{3}$ Aside from the fact that its viability is unusually low it is a typical recessive character.

At about the same time that acute was discovered the eye color mutant steel appeared (February I9I6) in a normal stock that had been kept separated from other stocks for several months. Until very recently this character, like concave, was thought to be greatly affected by cultural conditions, but it now appears that exposure to the air, especially warm air, after removal from the moist culture bottle, brings out the character and makes it possible to distinguish a large proportion of the steel individuals.

The mutant black appeared during May 1916 among the offspring of two separate pairs of flies, both derived from a single preceding culture (an axillary by morula cross). In both cases the ratio (approximately $3: 1$ ) indicates that the parents were heterozygous, and makes it probable that one of the grandparents was pure black. Two black females and one black male from one of the two pairs (number VI5I) when inbred gave in $F_{1}$ ten black offspring and a large number of blackcolored pupae that failed to hatch. The ten flies that did hatch were mated together and likewise produced a large number of larvae and pupae but only a few flies, all of which were black. Another culture of three flies, from this same bottle (VI5I) gave a large number of black flies with abnormal abdomens. These when inbred gave much the same result as the preceding, most of them producing only a few flies from among many pupae. One pair of black flies from the other original bottle (VI4I) showed a lower degree of mortality among its progeny. It produced 54 offspring (all black) in $F_{1}$, and two pairs of these gave 24 offspring in $\mathrm{F}_{2}$. But stock bottles made up from this are now showing a high degree of mortality similar to that in the other line. Apparently, then, the black factor has a partial lethal effect, or else a lethal factor of some sort is associated with it. Possibly the abnormal abdomen, found in many of the black flies, is an independent character and responsible for the mortality. If so, matings now being made ought to separate the two and give a viable black stock.

The remaining non-sex-linked character, bald, made its appearance in a confluent culture during January I9I6. The exact count was not obtained from this bottle, but subsequent breeding has shown bald to be a dominant character, completely or very closely linked with confluent. Unlike confluent, however, it does not always exhibit itself, and the

${ }^{3}$ Other morphological types of concave, such as those shown in figures 5 and 6 have likewise been tested, but are apparently all due to a single factor. 
bald class in nearly all matings is unduly small because some of the genetically bald flies appear normal. These features will be considered further under the heading of linkage.

It now remains to consider the four sex-linked characters yellow, glazed, magenta and forked. Yellow has appeared upon two occasions, first (July I9I5) in a single male that died without breeding, and second (January I9I6) in several males within one mass culture. These latter were successfully bred and gave rise to the present yellow stock. Yellow is a perfectly clear-cut character, breeding absolutely true, and showing typical sex-linkage. Its only peculiarity is its low viability, making it somewhat difficult to breed in pairs. When the original yellow males were mated to normal females they gave in $F_{1}$ only normal offspring, and in $\mathrm{F}_{2} \mathrm{I} 65$ normal females, 85 normal males and 79 yellow males. When yellow males were mated to heterozygous females they gave normal males and females and yellow males and females in approximately equal numbers. Similarly yellow females mated to normal males gave normal females and yellow males in equal numbers $(537: 544) .{ }^{4}$ Additional records involving yellow are given in the section on linkage.

Glazed is a character of recent origin (June 1916) and has not yet been studied extensively. It appeared in one male individual in a mass culture containing steel and normal. When bred to normal-eyed females this male gave in $F_{1}$ normal males and females, and in $F_{2} I 64$ normal females, 85 normal males and 44 glazed males. The $F_{2}$ females proved to be of two kinds, as expected,- one homozygous for normal eye, the other heterozygous for glazed. Mated to a normal brother one of the latter gave 36 normal-eyed females, i 8 normal-eyed males and I I glazed males. Another, mated to a glazed male, gave II normal females, I7 glazed females, I6 normal males and 9 glazed males.

During the same month in which glazed appeared (June I9I6) the character magenta was also found. It arose in acute stock, one pair of which gave 38 normal females, I9 normal males and 17 magenta males. No record was made of the eye color of the parents or grandparents in this case, but it is very probable that the mutation arose with the female used in this mating. Some of the original magenta males were mated to normal females, and others to yellow females. The former gave in $F_{1}$ only normal offspring, and in $F_{2} 90$ normal females, 43 normal males and 40 magenta males. The latter are considered in the next section

\footnotetext{
4 One of these matings gave, in addition, two yellow females and one normal male, apparently due to contamination or non-disjunction.
}

Genetics 1: N 1916 
under linkage. In addition, a number of the normal sisters of the original magenta males were mated to normals, and several gave magenta males in $\mathrm{F}_{1}$ showing that they were heterozygous for the magenta factor.

The other sex-linked character, forked, appeared in a single male individual (June 19I6) from a mating between confluent males and a normal female. When mated to normal females it gave in $F_{1}$ only normal offspring, and in $F_{2} 610$ normal females, 270 normal males, and 185 forked males. Like most of the other mutants it is less viable than normal, with the result that the mutant class falls below the expected proportion.

\section{LIN KAGE}

Among the above twelve characters three of the sex-linked and three of the non-sex-linked ones have been tested for linkage. The non-sexlinked characters are confluent, bald, and axillary, of which confluent and bald are closely linked together, while axillary shows no linkage with either. As has been previously noted, bald made its appearance in confluent stock. The bald confluent flies were mated to normals, and inter se, with the results shown in table 5. At first it appeared that crossing over took place in one direction, since some of the confluent flies in nearly every case had normal bristles on the head. But when these flies were tested by mating to unrelated normals they all gave bald offspring, showing that the apparent crossovers were due to the failure of bald to exhibit itself. A dozen or more flies were tested in this way and all gave the same results. It will also be noticed that in the table three flies are recorded in the normal wing bald class. These are flies in which one of the four bristles around the ocelli was gone, but the loss of a bristle was evidently purely accidental, for the flies proved to be genetically normal when tested by breeding. Up to the present time no known crossovers have occurred between these two factors.

The results of confluent by axillary matings have already been given in a previous section (table 3 ), and I need only note here the absence of linkage in this cross. The first four records, and probably several of the others given in table 3 , are from matings in which the confluent axillary parents received confluent and axillary from opposite sides, and should, if the characters were linked, give the effects of repulsion, i. e., confluent and axillary should appear mostly in different individuals, seldom in the same individual. Actually, however, the confluent axillary class is larger than the two others combined. Only the assumption of 
TABLE 5

Confluent bald (heterozygous) by normal, or inter se, in pairs.

\begin{tabular}{|c|c|c|c|c|}
\hline $\begin{array}{l}\text { Culture } \\
\text { number }\end{array}$ & $\begin{array}{l}\text { Normal } \\
\text { head } \\
\text { normal } \\
\text { wing }\end{array}$ & $\begin{array}{c}\text { Normal } \\
\text { head } \\
\text { confluent }\end{array}$ & $\begin{array}{c}\text { Bald } \\
\text { normal } \\
\text { wing }\end{array}$ & $\begin{array}{c}\text { Bald } \\
\text { confluent }\end{array}$ \\
\hline VI33 & $4 \mathrm{I}$ & 0 & I & 30 \\
\hline VI40 & 47 & 22 & I & 71 \\
\hline$V_{142}$ & 36 & 2 & I & 52 \\
\hline VI43 & 6 & 8 & 0 & 7 \\
\hline Vi46 & 24 & 2 & 0 & 19 \\
\hline$V_{149}$ & 33 & 2 & 0 & 36 \\
\hline VI67 & 17 & I & 0 & 22 \\
\hline VI8I & 7 & 0 & 0 & 9 \\
\hline$V_{204}$ & 15 & 0 & a & I4 \\
\hline V206 & 32 & 6 & 0 & 17 \\
\hline $\mathrm{V} 207$ & $3 I$ & 14 & 0 & 9 \\
\hline V209 & 33 & 29 & 0 & 13 \\
\hline V210 & 40 & 6 & 0 & 22 \\
\hline V2II & 31 & 24 & 0 & 14 \\
\hline $\mathrm{V}_{212}$ & $4 \mathrm{I}$ & I6 & 0 & 15 \\
\hline $\mathrm{V} 220$ & I 4 & I & 0 & 16 \\
\hline $\mathrm{V} 22 \mathrm{I}$ & 28 & 5 & o & 24 \\
\hline V222 & 34 & 8 & 0 & I5 \\
\hline$V 223$ & 33 & 3 & 0 & 23 \\
\hline V224 & 26 & 6 & 0 & II \\
\hline V237 & 50 & I 5 & 0 & I I \\
\hline$V_{242}$ & 20 & I I & 0 & I6 \\
\hline$V_{243}$ & 7 & 3 & 0 & 8 \\
\hline$V_{244}$ & 25 & 4 & 0 & IO \\
\hline V 247 & 29 & 9 & 0 & 23 \\
\hline V 249 & 34 & I I & 0 & I I \\
\hline $\mathrm{V} 267$ & $2 \mathrm{I}$ & 2 & 0 & 15 \\
\hline Total & 755 & 210 & 3 & 533 \\
\hline
\end{tabular}

very loose linkage, together with crossing over in both sexes, could explain such a result upon the basis of linkage; and since crossing over in the male has not been demonstrated in this species the assumption is very improbable.

In the group of sex-linked characters it has been possible to ascertain linkage values more rapidly than in the other groups, and three factors have already been located approximately. Or rather, two of them have been located with respect to a third. In both cases the linkage value is low, and the proportion of crossing over high. The first characters tested were yellow and glazed. Unfortunately only two cultures were made up from this cross and the numbers are very small, but in each 
case the crossover class is so large as to leave no doubt that the linkage is very loose.

The other characters are yellow and magenta. Males of the latter bred to females of the former gave in $F_{1}$ normal females and yellow males. The females bred to normal males gave normal females, and four classes of males in the proportion of 70 brown (body) red (eye), I 55 brown magenta, I 8 yellow red, and 89 yellow magenta. In this case, as in the former, the linkage is evidently loose, but here it is determined with greater accuracy and the percentage of crossing over may be said to be approximately 36 . Or, in the terminology adopted for Drosophila ampelophila, yellow and magenta are about 36 units apart.

Knowing the approximate linkage between yellow and glazed, and between yellow and magenta, it may now be predicted that if the factors compose a linear series in this species as they do in ampelophila the linkage between glazed and magenta will prove to be either relatively close, if they are both on the same side of yellow, or practically indistinguishable if they are on opposite sides.

\section{COMPARISON BE'TWEEN MUTANTS IN D. VIRILIS AND D. AMPELOPHILA}

Before turning to the mutants in other species it may be well to consider the relations between those just described and the known mutants in Drosophila ampelophila. Some of these relations have been mentioned in an earlier note (METz 19I6) but may be treated more fully here. The first and most striking feature is the apparent correspondence between some of the mutants found in virilis and those already known in ampelophila. The three characters, confluent, yellow and forked, for instance, are so similar to characters of the same name in ampelophila as to suggest at once that they are actual duplicates. In the case of confluent we have three different criteria that point to a correspondence in the two species. First the morphological characteristics, which are practically identical, second the fact that the character is dominant in both cases, and third that it has. a lethal effect when the fly is homozygous for it (see Bridges I9I6). The latter statement must be modified somewhat with respect to ampelophila, for confluent flies in that species show a very low viability and many fail to breed. It is possible, therefore, that some of these are homozygous. Likewise the number of offspring produced by confluent flies is so small as to make the ratios questionable; but so far as they go they resemble those in virilis. Through the kindness of Professor 
MorGan I secured, some time ago, a stock of confluent ampelophila and endeavored to test it out with respect to its lethal effect. The results, from the few pairs that could be induced to breed, are given in table 6 . Most of the confluent flies used as parents in these crosses were from confluent by confluent matings and theoretically one third of them should be homozygous. Actually, among the ten flies that bred, only one pair gave purely confluent offspring. Apparently one member at least of this pair was homozygous, unless the result was accidental. Unfortunately no $F_{2}$ flies were secured to make certain of the constitution of the $F_{1}$, and the evidence is not very conclusive.

TABLE 6

Confuent ampelophila.

a. Confuent by normal in pairs.

\begin{tabular}{c|c|c}
\hline $\begin{array}{c}\text { Culture } \\
\text { number }\end{array}$ & Normal & Confluent \\
\hline I228 & 19 & $\mathrm{I} 3$ \\
$\mathrm{I} 285$ & 33 & 15 \\
$\mathrm{I} 286$ & 45 & 33 \\
$\mathrm{I} 290$ & 25 & 24 \\
\hline Total & $\mathrm{I} 22$ & 85 \\
\hline
\end{tabular}

b. Confluent by confuent in pairs.

\begin{tabular}{c|c|c}
\hline $\begin{array}{c}\text { Culture } \\
\text { number }\end{array}$ & Normal & Confluent \\
\cline { 1 - 2 } $\mathbf{I} 288$ & 4 & 7 \\
1289 & 2 & 9 \\
$\mathbf{1} 279$ & 0 & 27 \\
\hline Total & 6 & 43 \\
\hline
\end{tabular}

These data are meager, but when taken together, and in connection with the fact that in ampelophila, as in virilis, no homozygous stock of confluent has been secured, it seems probable that the lethal effects as well as other features are similar in both species.

Turning to the two characters yellow and forked, it is to be noted especially that they are both sex-linked in each species. Yellow is slightly darker in virilis than in ampelophila (see Morgan 1912), but since the normal virilis is much darker than ampelophila this is to be expected if the factors really correspond. In the case of forked the morphological correspondence is complete even to the smallest detail, so far as I can tell from a careful comparison of the flies side by side.

So far as the evidence goes, then, it strongly suggests that the factors for confluent, forked and yellow in virilis are actually homologous to 
those in ampelophila. If this is true it follows, as indeed might be expected, that the germ plasms of the two species bear a definite structural resemblance to one another which we may hope to analyze experimentally. Furthermore, if these factors are really homologous, the fact that yellow and forked are sex-linked in each species would indicate that the structural relations of the germ plasm so far as the factorial arrangement is concerned are alike or similar in the two species. And if this is the case it is difficult to avoid the conclusion that there is a genetic continuity of germinal structures-in all probability chromosomes-in these flies.

When the linkage relations between these respective factors are known the evidence will be much more definite; but even if the linkage values are not the same in the two species it does not necessarily mean that the organization is different, for the amount of crossing over might be very different in different species. The crucial test will be to determine whether a linear series similar to that in ampelophila is present in virilis.

MUTATIONS IN DROSOPHILA OBSCURA FALL.

My studies upon Drosophila obscura are still in their initial stages and may be passed over with a brief description of the three mutants at hand. The first is characterized by the presence of from one to four extra bristles on the scutellum. It was first observed in October 191 5 when several extra bristle flies of both sexes appeared in a mass culture. Subsequent matings have shown it to be a non-sex-linked recessive, but one which is very dependent upon environmental conditions for its manifestation. Table 7 illustrates a typical series of results obtained from homozygous flies mated in pairs. As will be noted some of the pairs give nearly Ioo percent of extra bristle offspring, while others give a very much lower percentage. No systematic attempt has been made to determine the agent responsible for these deviations, but it has been noted that in almost every case the higher percentages of extra bristle flies are found in well fed, moist cultures, and the lower percentages in poorly fed, dry cultures.

In the second mutant, triangle, the posterior cross vein forks and forms a triangle at its junction with the fourth vein. This character appeared during February I9I6 among the offspring of two separate pairs of flies from a single preceding culture. One of the pairs gave I5 triangle and about 75 normal offspring. The other gave 7 triangle and several normals (exact number not recorded). Two matings of 
TABLE 7

Drosophila obscura, extra bristle stock inbred in pairs.

\begin{tabular}{|c|c|c|}
\hline $\begin{array}{l}\text { Culture } \\
\text { number }\end{array}$ & $\begin{array}{l}\text { Extra } \\
\text { bristle }\end{array}$ & Normal \\
\hline 2191 & It & 8 \\
\hline $02 \mathrm{I}$ & 20 & 75 \\
\hline 022 & I 8 & 120 \\
\hline 029 & $2 \mathrm{I}$ & 60 \\
\hline 030 & 34 & 30 \\
\hline O3I & 24 & $9 \mathrm{I}$ \\
\hline 032 & 28 & 29 \\
\hline 033 & 39 & II5 \\
\hline 034 & 50 & 103 \\
\hline 037 & 24 & 33 \\
\hline 038 & 3 & 33 \\
\hline 040 & II & 80 \\
\hline $04 \mathrm{I}$ & I I & 19 \\
\hline 049 & I I & 39 \\
\hline $05 \mathrm{I}$ & 58 & 6 \\
\hline 052 & 16 & IO \\
\hline 057 & 17 & I \\
\hline $06 \mathrm{I}$ & 21 & 3 \\
\hline Total & 423 & 8.5 \\
\hline
\end{tabular}

triangle by triangle from these gave respectively 66 triangle: 5 (questionable) normal and I9 triangle: 3 normal. In each case some of the females may have mated with normal males before the cultures were made up, $-\mathrm{a}$ fact that may account for the normals in their progeny. Judging from these preliminary data it seems probable that the character will prove to be a simple, true-breeding recessive.

The third mutant is characterized by abnormally short veins in the wing. Both the fourth and fifth veins fail to reach the margin, and occasionally the posterior cross vein is broken. The character is a sexlinked recessive. It appeared during July 1916 in nine males from a mass culture containing extra bristle flies. These males, bred to normal females, gave in $F_{1}$ normal males and females, and in $F_{2} 8_{I}$ normal females, $3^{8}$ normal males and $3^{8}$ short vein males. No $F_{3}$ flies have been obtained yet, but the character appears to be regular in its behavior.

AN EYE COLOR MUTANT IN DROSOPHILA SIMILIS WILL.

Most of the mutants in Drosophila ampelophila and in the species just considered, have arisen in more or less highly inbred stock, and it is consequently of interest to note any that have not. Several have already been recorded (Hyde I9I 5 a, Sturtevant I9I 5 ), and the following is an 
additional one. It is distinguished by the possession of chocolate-colored eyes instead of bright red eyes. Flies having this eye color appeared in either the first or second generation of descendants from a normal wild female of Drosophila similis that I collected in Cuba. Since the species has never before been bred in captivity there is little chance that inbreeding could have had anything to do with the origin of the mutant in my cultures. The following is a brief history of the character in respect to its origin and behavior: Progeny of a single wild female were transferred without examination, to stock bottles. One of these bottles, examined after the next generation appeared, contained approximately equal numbers of chocolate and red-eyed flies. Three normal females from this, mated to chocolate males, gave 8 chocolate and 7 normal offspring. Five other normal females mated to five chocolate males gave 37 chocolate and 35 normal offspring. Four mass cultures of chocolate flies bred true and gave nothing but chocolate-eyed progeny, (more than IOO), as did succeeding cultures of pure stock.

\section{MUTABILITY IN DIFFERENT SPECIES OF DROSOPHILA}

In conclusion a word may be said concerning the individual mutative tendencies of the different species of Drosophila thus far studied. The rapid appearance and varied characteristics of mutations in Drosophila ampelophila have given rise to the natural impression that this species possesses a peculiar tendency to mutate, not shared by even its close relatives. It is not at all surprising that this opinion has arisen, considering the extraordinary number of mutations obtained from ampelophila, but in view of the recent mutations in some of the other species it becomes much less probable that the mutating capacity is peculiar to the one fly. Mutations have now been recorded in six other species,-two in repleta (Hyde I9I5 a, Sturtevant I9I5), one in confusa (Hyde 1915 b), one in tripunctata (Metz and MeTz I915), twelve in virilis (present paper), three in obscura (present paper), and one in similis (present paper). These leave no doubt that species other than ampelophila have at least some capacity for mutating. Whether this is true of all Drosophilas is, of course, a question, but the fact that mutations have appeared in nearly all the species studied extensively, and in some studied only superficially, tends strongly toward an affirmative answer. In a like manner the evidence furnished by virilis and obscura tends to modify the conclusions respecting the relative rapidity of mutation in the various species. Of course it is impossible to get more than a rough estimate of the total number of flies examined in any of these species, 
but since my cultures of virilis alone have given rise to at least a dozen mutations within the last year ${ }^{5}$ there can be little question that this species mutates approximately as fast as does ampelophila. And in obscura the rate can not be greatly different, for here three mutations have already been found among a relatively small number of flies examined.

Taking all of these facts together it seems not improbable that most, if not all, Drosophilas are essentially alike in respect to their tendency to mutate, and that a series of mutations could be found in any of them if sufficiently large numbers of individuals were examined.

5 Two new ones have appeared since the first part of this paper was written.

\section{LITERATURE CITED}

BRIDGES, IC. B., I9I6 Non-disjunction as proof of the chromosome theory of heredity. Genetics $1: 1-52$, I07-163.

Hyde, IR. R., r9I5 a The origin of a new eye color in Drosophila repleta, and its behavior in heredity. Amer. Nat. 49:183-185.

$1915 \mathrm{~b} A$ wing mutation in a new species of Drosophila. Amer. Nat, 49 : 185-187.

Metz, C. W., I9I6 Linked Mendelian characters in a new species of Drosophila.' Science N. S. $44: 43 \mathrm{I}-432$.

Metz, .C. W., and Metz, B. 'S., I9I5 Mutations in two species of Drosophila. Amer. Nat. 49 : $187-189$.

Morgan, T. H., IgI2 Heredity of body color in Drosophila. Jour. Exp. Zoöl. $13: 27-44$.

Morgan, Sturtevant, Muller and Bridges, igr5 Mechanism of Mendelian heredity. xiii +262 pp. New York: Henry Holt \& Co.

S'turtevant, A. H., I915 A sex-linked character in Drosophila repleta. Amer. Nat. 49: I9O-I9I. 